\title{
Glyburide was as safe and effective as insulin in gestational diabetes
}

\author{
Langer $O$, Conway $D L$, Berkus $M D$, et al. A comparison of glyburide and insulin in women with gestational diabetes \\ mellitus. N Engl J Med 2000 Oct 19;343:1134-8.
}

\section{QUESTION: Is glyburide as effective and safe as insulin in women with gestational diabetes mellitus?}

\section{Design}

Randomised (allocation concealed*), unblinded,* controlled trial.

\section{Setting}

Maternal health clinics in San Antonio, Texas, USA.

\section{Patients}

404 women (mean age 29.5 y) who were between 11 and 33 weeks of gestation with a singleton pregnancy and who had gestational diabetes and fasting blood glucose concentrations $\geqslant 5.3 \mathrm{mmol} / \mathrm{l}$ and $<7.8 \mathrm{mmol} / \mathrm{l}$. Follow up was $100 \%$.

\section{Intervention}

404 women were allocated to receive glyburide $(n=201)$ or insulin $(n=203)$. Glyburide was started at an oral dose of $2.5 \mathrm{mg}$ and increased to $20 \mathrm{mg}$ as needed. Insulin was started at a dose of $0.7 \mathrm{U} / \mathrm{kg}$ of actual body weight, given subcutaneously 3 times/day, and increased as needed. All women were given standard nutritional instructions for 3 meals and 4 snacks daily.

\section{Main outcome measures}

The primary outcome was the achievement of prespecified levels of glycaemic control. Secondary outcomes were maternal and neonatal complications.

\section{Main results}

Analysis was by intention to treat. At a mean of 10.5 weeks of testing, the glyburide and insulin groups did not differ for mean daily blood glucose concentrations (5.9 v $5.9 \mathrm{mmol} / \mathrm{l}, \mathrm{p}=0.99)$ or mean glycated haemoglobin $(5.5 \%$ $5.4 \%, \mathrm{p}=0.12)$. The glyburide and insulin groups did not differ for the rate of infants who were large for gestational age $(12 \% v 13 \%, \mathrm{p}=0.76)$, had macrosomia defined as a birth weight $\geqslant 4000 \mathrm{~g}(7 \% v 4 \%, \mathrm{p}=0.26)$, or had hypoglycaemia $(9 \% v 6 \%, \mathrm{p}=0.25)$ or for those who had cordserum insulin concentrations $(15 v 15 \mu \mathrm{U} / \mathrm{ml}$, $\mathrm{p}=0.84) .8$ women in the glyburide group $(4 \%)$ were switched to insulin therapy because the maximal glyburide dose failed to produce good glycaemic control.

\section{Conclusion}

Glyburide was as safe and effective as insulin in the treatment of women with gestational diabetes mellitus.

*See glossary.

\section{COMMENTARY}

Diet counselling is the appropriate initial approach to managing gestational diabetes mellitus. If hyperglycaemia persists in these patients, insulin is the current recommended treatment. Older studies have shown that transplacental passage of some hypoglycaemic agents and consequent neonatal hypoglycaemia occur. ${ }^{1}$

The elegant study by Langer et al shows that glyburide does not cross the placenta and therefore would not increase the risk for neonatal hypoglycaemia or large for gestational age infants. The higher molecular weight of glyburide is likely the reason for the lack of transplacental passage. Groups did not differ for glucose control; however, fewer episodes of maternal hypoglycaemia occurred in the glyburide than in the insulin group $(2 \% v 20 \%, \mathrm{p}=0.03)$. The starting dose of insulin was large, and a lower initial dose given 4 times daily may have reduced the episodes of maternal hypoglycaemia and led to better glucose control. ${ }^{2}$ Although not statistically significant, both neonatal hypoglycaemia and macrosomia tended to occur less often in the insulin group; larger numbers may be required to examine whether this trend is real.

What should we tell patients with gestational diabetes? The few patients who develop new onset diabetes in the first trimester should not be given oral hypoglycemic drugs because of possible teratogenicity. Metformin is contraindicated for gestational diabetes because of the associated increased risk for perinatal mortality. ${ }^{3}$ Patients with gestational diabetes who have fasting hyperglycaemia after the first trimester now have a choice in their treatment. If they wish to avoid insulin injections (a mode of treatment that has a known safety profile, gives greater flexibility, and with insulin pens is easy to use), glyburide appears to be a reasonable option.

Edmond A Ryan, MD
University of Alberta
monton, Alberta, Canada

1 Piacquadio K, Hollingsworth DR, Murphy H. Effects of in-utero exposure to oval hypoglycaemic drugs. Lancet 1991;338:866-9.

2 Nachum Z, Ben-Shlomo I, Weiner E, et al. Twice daily versus four times daily insulin dose regimens for diabetes in pregnancy: randomized controlled trial. BMJ 1999;319: 1223-7.

3 Hellmuth E, Damm P, Molsted-Pedersen L. Oral hypoglycaemic agents in 118 diabetic pregnancies. Diabet Med 2000;17:507-11.
Source of funding: not stated.

For correspondence: Dr $O$ Langer, Department of Obstetrics and Gynecology, St Luke's-Roosevelt Hospital Center, 1000 10th Avenue, New York, NY 10019, USA. Fax +12125238066. 